INTERNATIONAL DESIGN CONFERENCE - DESIGN 2018

https://doi.org/10.21278/idc.2018.0520

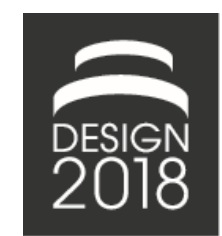

\title{
MARGINS LEADING TO OVER-CAPACITY
}

\author{
D. A. Jones, C. M. Eckert and K. Gericke
}

\begin{abstract}
This paper categorises and describes the design stages, stakeholders and decision processes of an overcapacity boiler upgrade that came about from the excessive use of design margins. Using a hospital case study, the reason behind the overcapacity and excessive margins is explored using semi-structured interviews, document analysis and process modelling. Design margins arise from a lack of systemic thinking during the design and installation phases. It is likely that margins are added as a matter of habit with no real thought to their applicability, calling into question the design process.
\end{abstract}

Keywords: design process, case study, decision making, design margins, energy efficiency

\section{Introduction}

Operating an overcapacity system often has hidden effects that cause higher than necessary energy consumption. This paper explores the design stages, stakeholders and decision processes of an overcapacity hospital boiler upgrade that came about from the excessive use of design margins. The addition of design margins can lead to the surplus that parameters, components or systems have above and beyond their current requirements. In engineering design, margins are added deliberately to mitigate risks, such as changes to the product or its requirements. Design margins may also be added because the actual capability of a product is unknown, i.e. the surplus is larger than expected, or arises because an existing solution is reused, for example from a platform. Margins also play a large role in construction projects and within building services design (i.e. heating, cooling and ventilation systems). In Jones and Eckert (2016) we argue that potentially very large margins can be added following building design guidelines. This paper looks at a hospital case study of a boiler upgrade that is significantly over-engineered by a factor of four over the required capacity. Whilst it is apparent that very large margins have been applied, it is not entirely clear how the margins are accumulated within the design processes. In order to address this issue in future design projects, it is important to fully understand the decision-making processes leading to the overdesign, hence empirical research of this paper looks at the decision-making processes to establish why the margins have been applied, where during the design process they have been added, and by whom. In building services, margins are applied across the various stages of specification, design and installation, often without the various stakeholder groups being aware that margins have been added. Whilst the excessive use of margins leading to overdesign is a frequent topic of discussion within building services and is generally recognised as being problematic, this issue is not being systematically addressed. Projects are initiated by the development of a client specification; this specification often takes account of future needs and provides a general brief of the project requirements. This client brief forms the basis of the detailed engineering design that follows. During the detailed design process, margins are applied from 'custom and practice' within manual engineering calculations; less apparent margins are also applied during the use of design software to allow for uncertainties and safety tolerances. Bownass in his 2001 book 
states that "there is little authoritative reference on the actual margin to be applied in any specific application and although there are good reasons to applying design margins (future use requirements, installation tolerances, theoretical fabric design $U$ values, etc.) that any objective figure can be debated" (Bownass, 2001).

Design margins are particularly interesting when considering their impact on energy efficiency. The Climate Change Act 2008 currently provides a strong legal necessity to properly ensure energy infrastructure within buildings operates at the optimum conditions for efficiency, yet the continued practise relating to the application of excessive margins during the design and installation of building service systems, is leading to significantly over-engineered, over-sized plant that is incapable of operating at its optimum efficiency point. The paper argues that design margins are added by multiple stakeholders throughout the design process, very often through habit, custom and practise as precautionary measures without any real thought of the 'oversizing' consequences. The research background and the use of design margins are discussed in section two, the research methodology is presented in section three and the research case study is detailed in section four. The lack of process coordination as a possible reason for the margins is considered in section five, and section six discusses three alternative explanations of how margins may have accumulated within the case study example, and points to the lack of documentation or rationale associated with the margins applied. The paper draws conclusions in section seven.

\section{Background}

The issue of hospital engineering systems overdesign within the context of this paper originated from wider PhD research looking at strategic energy management in National Health Service (NHS) hospital Trusts. In the case of NHS hospital buildings, the necessity for long-term use and other possible external influences must be considered. Due to financial constraints within the UK government, private finance initiative (PFI) contracts have paved the way for the development of much needed new hospital buildings; a scenario that is central the case study example detailed within this paper. PFI building contracts generally have a minimum 30-year term, however the need for these buildings will not disappear after this period of contract; they will need maintaining and continue to be used in some capacity. De Neufville et al. states that in general terms, "these complex devices require enormous efforts. They are likely to have significant, long-term roles in our society" (de Neufville et al., 2004).

\subsection{Design margins}

While the term 'margin' is often used within companies in a number of industry sectors, particularly in the aerospace or ship building industry (Stratmann, 2006), it has so far not been formally defined. A useful definition of a design margin is: "the extent to which a parameter value exceeds what it needs to meet its functional requirements regardless of the motivation for which the margin was included" (Eckert et al., 2013), which are added by different stakeholders for a variety of reasons. In the context of mechanical engineering, design margins are added to provide flexibility; flexibility itself being defined as providing "functionality, performance, and capacity" each of which "consists of many attributes, which can also be thought of as requirements" (Banerjee and de Weck, 2004). The flexibility of a product can be assessed by systematically anticipating and rating the potential future changes to "future proof" the design, which will inevitably introduce a degree of overdesign into the product (Ross and Hastings, 2005). De Neufville et al. (2006) advocates "design options" as a form of deliberate planning for anticipated changes, which is costed and deliberately decided upon. Looking at margins

from the perspective of overdesign that exists, Tackett et al. (2014) address margins in the context of shipbuilding in terms of excess, as "the quantity of surplus in a system once the necessities of the system are met" and capacity as "the ability of a system to meet future performance objectives using existing system excess". With regard to building services engineering, design margins are primarily applied to safeguard against uncertainty and risk (CIBSE, 1986), however this practise often leads to overengineered solutions. Bacon determines "that building energy performance directly relates to the engineer's assumptions based upon occupancy levels, which are often standardised, leading to overengineered systems for maximum occupancy levels" (Bacon, 2014). Other research determines "The 
widespread use of simple sizing tools - "previous experience" and rules-of-thumb - could be an indication of why oversizing is so prevalent" (Djunaedy et al., 2011). Often "many decisions are made at detail level, with limited consideration of overall solutions and overall performance/cost ratio" (Almefelt, 2005).

Whilst a large range of margin values are quoted within building services guidance documents, there is little published guidance on the definitive use of these margins, hence design engineers are left to decide where and to what extent to apply the margins, based on past practise and experience. An industry research report published by the Chartered Institute of Building Service Engineers (CIBSE) revealed that design margin values used for similar applications varied considerably across multiple documents (CIBSE, 1998). Table 1 includes findings from this research report (CIBSE, 1997) and provides a summary of typical margin parameters applied and the various margin values quoted in literature. The report highlights the fact that whilst guidance publications often quote typical margins used, they do not make specific recommendations as to which values to use; interestingly, the report also states that the origin of many of the margins quoted were difficult to determine, pointing to a degree of "custom and practice" built up over a long period of time.

Table 1. Margins quoted in literature - Heating Ventilation \& Air Conditioning

\begin{tabular}{|l|l|l|}
\hline Parameter & Range of values & Values quoted \\
\hline Heat losses & $10-15 \%$ & $10 \%, 15 \%$ \\
\hline Boilers & $10-25 \%$ & $10 \%, 20 \%, 25 \%$ \\
\hline Boiler pre-heat margin & $10-200 \%$ & $10 \%, 20 \%, 33 \%, 100 \%, 200 \%$ \\
\hline Pumps - flow and pressure & $10-25 \%$ & $10 \%, 20 \%, 25 \%$ \\
\hline Fans - flow and pressure & $10-30 \%$ & $10 \%, 15 \%, 20 \%, 30 \%$ \\
\hline Plant & $0-30 \%$ & $10 \%, 15 \%, 30 \%$ \\
\hline
\end{tabular}

Based on the aforementioned research undertaken by CIBSE, it is safe to assume that there are opportunities within the design and installation process to carefully apply margins that lead to a robust solution, but also to ensure that cumulative margins do not result in an over-engineered solution. From an energy efficiency perspective, an over-engineered building services system is likely to be too large to operate at its optimum efficiency point (Djunaedy et al. 2011, Bacon, 2014). A Building Services Research and Information Association (BSRIA) guide to building services calculations states that "margins should never be added during a calculation process without an adequate reason for doing so and with the approval of a senior engineer" furthermore "if any margins are used they should be clearly identified and a justification given for their use" (BSRIA, 2007). Despite BSRIA producing guidance on the use of engineering design margins for building services through the promotion of better design consistency and standards (Race, 2007), it is evident from the hospital boiler case study and the authors professional practise working within the building services industry, that this guidance is largely being ignored and that the practise of applying excessive margins continues to be accepted. A study undertaken by BSRIA across fifty heating, ventilation and air conditioning (HVAC) systems in the UK were monitored and analysed to establish the extent of oversizing. It was found that " $80 \%$ of the heating plant, $88 \%$ of the ventilation plant and $100 \%$ of the chiller plant incorporated capacity above that necessary to meet design requirements" (Crozier, 2000). A summary of the findings is illustrated in Figure 1, where an oversizing factor of one represents 'ideal' requirements, and excess capacity is denoted by a series of solid bars, up to a maximum oversizing factor, is in excess of five.

Despite this study being undertaken in 1999, there is still clear evidence that over-sizing of building services systems remains a significant issue. 


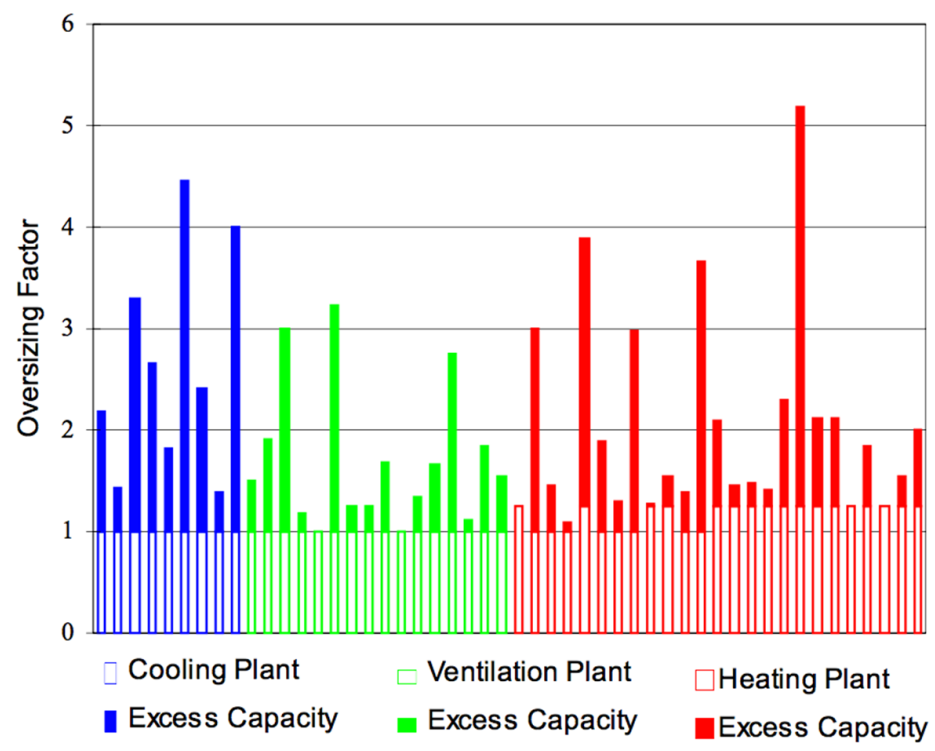

Figure 1. Summary of oversizing in 50 HVAC systems

\subsection{Redundancy principles in building services}

The application of a redundancy factor within building services design is to ensure reliability in the event of a full and partial system failure (Chen and Crilly, 2014). Having more boilers than is necessary to meet the site maximum demand is an example of system redundancy, an example that provides key discussion points and the practical research contribution of this paper. The degree of redundancy applied is dependent upon a building's risk and resilience requirements. In domestic type, residential buildings redundancy is rarely applied, in hospital buildings $\mathrm{N}+1$ redundancy tends to be applied; that is, the redundancy of a single boiler $[\mathrm{N}]$ for example, is substituted by a boiler of matched capacity $[+1]$. Building services plant such as data centre cooling systems having $\mathrm{N}+2$ redundancy, is not uncommon. That said, the adoption of this principle should be applied with care, as an excessive redundancy factor can give rise to a significant margin category that leads to operational inefficiencies (e.g. losses attributed to semi-dormant equipment in 'standby' mode). Typically, the above redundancy scenarios utilise building service systems on a like-for-like basis, rather than consideration being given to the use of alternative technologies. The related concepts of segregation and diversity also provide an element of resilience, whereby segregation works on the basis that total system failure is less likely if its component parts are located physically away from one another, and that diversity provides resilience on the basis that different system types are used to provide a common function (Möller and Hansson, 2008).

\section{Methodology}

This research included semi-structured interviews and document analysis. The interviews with a range of decision-makers across the hierarchy of the hospital Trust, between February and September 2015 were semi-structured to allow the interviewees to explain 'how and what' influences impacted their ability to implement energy reduction measures within the organisation. Ensuring participants' anonymity also provided space for them to talk frankly, particularly where organisational constraints were perceived to negatively affect the decision-making process. Nine interviews were conducted initially, whereby general discussions regarding the hospital's 'strategic energy management' practices opened up further conversations regarding concerns over an inefficient, overcapacity boiler design which had been specifically upgraded to meet the requirements of a new private finance initiative (PFI) building contract specification (the private finance initiative (PFI) is a way of funding public infrastructure projects with private capital, this is explained in more detail within Section 4).

As the boiler house example grew in significance, a further two interviews were organised; one with a Trust-side project engineer directly involved in the boiler design scheme and another, with an experienced building services design consultant. 
Table 2. List of relevant interviewees, in chronological order

\begin{tabular}{|c|c|c|c|c|}
\hline Interview no. & Job Title & Date & Duration & Interviewer \\
\hline P1 & Deputy Director for Corporate Services & $12 / 02 / 2015$ & 48 minutes & DJ, CE \\
\hline P3 & Estates Operation Manager & $12 / 02 / 2015$ & 63 minutes & DJ, CE \\
\hline P4 & Energy Manager & $12 / 02 / 2015$ & 54 minutes & DJ, CE \\
\hline P8 & Estates Development Manager & $20 / 04 / 2015$ & 34 minutes & DJ \\
\hline P10 & Senior Project Manager & $16 / 09 / 2015$ & 20 minutes & DJ \\
\hline P11 & Chartered Building Services Design Engineer & $28 / 09 / 2015$ & 45 minutes & DJ \\
\hline Validation P12 & Advisor to the Private Finance Unit & $09 / 11 / 2017$ & 35 minutes & DJ \\
\hline Validation P13 & Estates Operation Manager & $09 / 11 / 2017$ & 12 minutes & DJ \\
\hline
\end{tabular}

These interviews covered general engineering conversations, such as what and how heuristic parameters are applied during a boiler-house design process, as well as more specific conversations about the boiler example. Table 2 lists interviews where conversations specifically arose relating to the boiler design project. The remaining five non-technical interviews P2, P5, P6, P7 and P9 are excluded from this table. All interviews were recorded and subsequently transcribed. Most were face-to-face, with the exception of the interview with the external design consultant which was facilitated via a telecom call; notes were taken, capturing the salient points discussed. The interviews provided a useful overview of the decision processes specific to the boiler-house design, highlighting key influences over the design specification, limitations in technical knowledge and a general acceptance of the boiler over-capacity. Due to the long time lapse between project completion and the research interviews, external consultants and other key people involved in the boiler design could not be contacted for the research. Therefore, some gaps should be presumed to exist within the overall picture of the project development, which could also not be filled by the remaining internal people.

In addition to the research interviews, a document review was also undertaken. In the author's capacity as an independent energy consultant to the Trust, full access to project documentation was provided. The focus of the document review was to establish what factors during the design process had led to the over sizing of the boiler plant, and what margins had been applied. A total of 567 documents were reviewed, these were understood to represent the entire project database, which included; site plans and mechanical service drawings, project correspondence, cost and budget documentation, scope of works, project plan schedules, health and safety records, minutes of project meetings, tender documents and technical specifications, all specific to the boiler house project. The review was carried out using key 'word' searches (e.g. capacity, heating load, $\mathrm{kWh}$ ) via programme toolbars, within a pdf. reader and Microsoft Word. A large proportion of the documents were scanned images, and so not compatible with the search function; these documents were instead, skim read. Where areas of potential interest were identified, text was studied in greater detail. Based on information derived from the interviews and document review, the authors modelled the design process to pin point stakeholders that made the decisions to add margins, at what point the margins were added and why they were added. The resulting swim lane diagram clearly identified some gaps in our understanding, which prompted further validation interviews to take place with an advisor to the NHS Private Finance Unit (PFU) and the hospital Estates Operation's Manager (Interviews - P12 \& P13). The validation interviews where undertaken via telecom calls, whereby structured questions were presented and notes were taken. The notes were subsequently typed up and the findings used to provide a more complete picture of the design process, represented by a second iteration, swim lane diagram.

\section{Design margins in building service engineering}

Design margins are cumulative, as they are added for a number of reasons. CIBSE guidance documents quote typical margin parameters that are added for different reasons, such as calculation accuracy, wear and tear, safety, resilience, future proofing etc. (See Table 1). These typical margins can add up to $300 \%$ overcapacity, and would explain the $400 \%$ overdesign of the case study example. 


\subsection{Stakeholders involved in the design project}

Healthcare in the UK is provided by the National Health Service (NHS). The NHS has individual branches for England, Scotland, Wales, and Northern Ireland, each subordinate to its respective government (Department of Health and Secretary of Health). The NHS is the umbrella organisation to the NHS trusts. Different types of trusts are responsible for different services, e.g. hospital trusts, mental health trusts, ambulance service trusts. Each trust accounts for all related healthcare services in a certain geographical area (NHS, 2017). Due to its enormous size and complexity, the NHS can be seen as a complex adaptive, system-of-systems (SoS) characterised by autonomy (operational and managerial independence), connectivity and diversity which consequently leads to poor communications and a lack of collaboration (Boardman and Sauser, 2006). Hospital trusts are responsible for the planning, design and operation of hospitals. A means to support the NHS trusts in this mission are Private Financed Institutions (PFI). PFIs are contracted private organisations that take responsibility for the planning and construction of buildings. The outsourcing of building design projects and the management of finished buildings was meant to improve efficiency of the NHS system. However, it is heavily debated if PFIs improve efficiency or have become a burden to the NHS (The Telegraph, 2017).

The Public Private Partnership (PPP) scheme between NHS Trusts and PFIs leads to the situation that one hospital might use buildings that are owned by either an NHS Trust or by a PFI. Complex contract terms between NHS Trusts and PPP/PFI operators can lead to legal complications and financial penalties associated with the ownership of responsibility and risk. This becomes a challenge especially for refurbishment of critical infrastructure that is being used by different buildings such as heating systems. The boiler house in this case study has to provide heating to an existing hospital complex owned by an NHS Trust and to a new hospital building that is financed, owned and operated by a PFI consortium, referred to as a 'single integrated supply team' (SIST). The appointment of the SIST was the responsibility of the Trust (Interview P13), however this required approval by the Private Finance Unit (PFU), a Government unit within the Department of Health (Interview P12). The execution of the hospital design project was delegated by the PFI to a contracting company (main contractor). The main contractor bears responsibility for the actual design work and implementation and hires sub-contractors for individual parts of the project whenever necessary. The design of the boiler-house upgrade remained the responsibility of the Trust, who appointed their own design consultants to meet the specific capacity requirements of the PFI hospital, as well as that of the site retained estate.

From careful analysis of the data, it was established that in excess of 60 stakeholders (sub-contractors) were involved in the boiler upgrade project, over the course of a decade. The main categories of stakeholders associated with the design and installation of the hospital development and boiler upgrade were:

- the NHS Trust

- the PFI consortium (single integrated supply team)

- the main contractors (for both the PFI hospital and boiler project)

- the sub-contractors

Design interactions, contributions and decision points of these main stakeholders were modelled and captured within a swim lane process diagram, the outcomes of which are discussed in the next section.

\subsection{Design margins specific to the case-study boiler upgrade}

The case study example of a boiler upgrade within an NHS hospital revealed that that thermal capacity of the boiler house is more than four times the peak energy need of the hospital site (Jones and Eckert, 2016). Despite a thorough review of 567 boiler upgrade related documents, only a single paper entitled 'Energy Centre Report (ECR)' dated 20th December 2006 was found to provide some evidence as to the boiler sizing rationale. The report provided details of the heating load requirement for the hospital PFI development, stating a total heat load of $9,513 \mathrm{~kW}$ was necessary, and that this figure had been based on outline design calculations that included an $8 \%$ uplift to account for heat distribution losses; incidentally the allowance for distribution losses was the only documented margin available within 
the entire project file. No engineering calculations or decision process notes were provided in support of these figures. Despite having undertaken a number of semi-structured interviews, a thorough document review and having modelled the decision-making process all in relation to the boiler upgrade project, the authors were unable in any detail to ascertain how the margins, and oversizing had arisen.

The ECR report also stated that no thermal capacity provision had been made for the site retained estate, nor the Trust owned maternity and oncology new-builds. From interview transcripts, it is understood that the final boiler capacity requirement specified by the PFI project team for the 'hospital PFI development' only, was $12 \mathrm{MW}$, and although the Trust engineering team did challenge this at the time (as this capacity appeared rather excessive), the PFI project team was insistent on this requirement. Despite the Trust management team taking advice, due to the risks associated with them not meeting their PFI contractual obligation (i.e. to provide enough heat to the PFI hospital installation) and secondly, to ensure the PFI programme was not delayed, the $4 \mathrm{MW}$ boilers were removed, and replaced by three $8.2 \mathrm{MW}$ boilers, having a total installed capacity of $24.6 \mathrm{MW}$. When considering the additional thermal requirement of Trust retained buildings, there was a consensus amongst those staff interviewed, that the boiler sizing rational was based on two $8.2 \mathrm{MW}$ boilers to satisfy the anticipated thermal requirement of $16 \mathrm{MW}$ (12 MW for the PFI hospital + 4 MW for Trust retained buildings) and a third 8.2 MW boiler to provide $\mathrm{N}+1$ redundancy, should one of the two duty boilers become unavailable. This logic was supported by the tender specification that states "the work comprises of replacing three LTHW boilers with three boilers of increased capacity". From discussions with Trust staff (Interviews - P3, P4, P10) it is understood that total current peak thermal demand for the hospital site is between 5 and $6 \mathrm{MW}$ during peak winter, from a combination of old and new Trust retained buildings, and newly constructed PFI estate; hence, whilst three boilers of $8.2 \mathrm{MW}$ were installed, one boiler would easily cover the need.

The energy performance and cost implications of the oversized system is substantial, this is largely due to excessive boiler standing losses (radiated heat losses from the surface of the boiler and chimney) and boiler cycling (frequent on/off operation), which when combined with the fact that the boilers were fitted with inefficient burners, has significant implications on the boiler system's ability to operate efficiently, thus impacting on the Trusts ability to meet statutory carbon reduction targets. It is understood that whilst efficient burners were originally specified at the design stage, these were value engineered out by Trust Senior, non-technical Managers.

\subsection{Modelling the design process}

A process model was developed to capture and reconstruct the key stakeholders and work activities of the boiler upgrade design process, which is based on information deduced from project documentation and eight semi-structured interviews. A Microsoft 'Excel' based stakeholder analysis was initially produced from the review of each project document (567 in total), recording the relevant stakeholder, dates of participation and tasks undertaken. On completion, the Excel file was filtered in order of stakeholders to determine the number of project contributors and participation timelines. In parallel with this, transcripts from the semi-structured interviews were reviewed to establish the involvement of higher level, strategic stakeholders and the decision processes that occurred. All resulting information was presented and used to develop a simplified model of the process, which is illustrated in Figure 2.

As seen from the model, the process was initiated by the NHS Trust based on the requirements of a new hospital building. The Trust selected the PFI consortium (SIST) via a tender process after gaining approval from the Department of Health's private finance unit. The PFI consortium, made up of a number of private sector organisations (financiers, construction companies etc.) nominated a main contractor to design and build the new hospital. The main contractor then commissioned, via formal procurement mechanisms, sub-contractors to deliver various elements of the construction project. In conjunction with the hospital new build, the design and installation of the boiler upgrade, which remained the responsibility of the Trust, was awarded to a building services contractor via a formal tender process, to a meet the specific needs of the PFI hospital, as well as that of the site retained estate. 


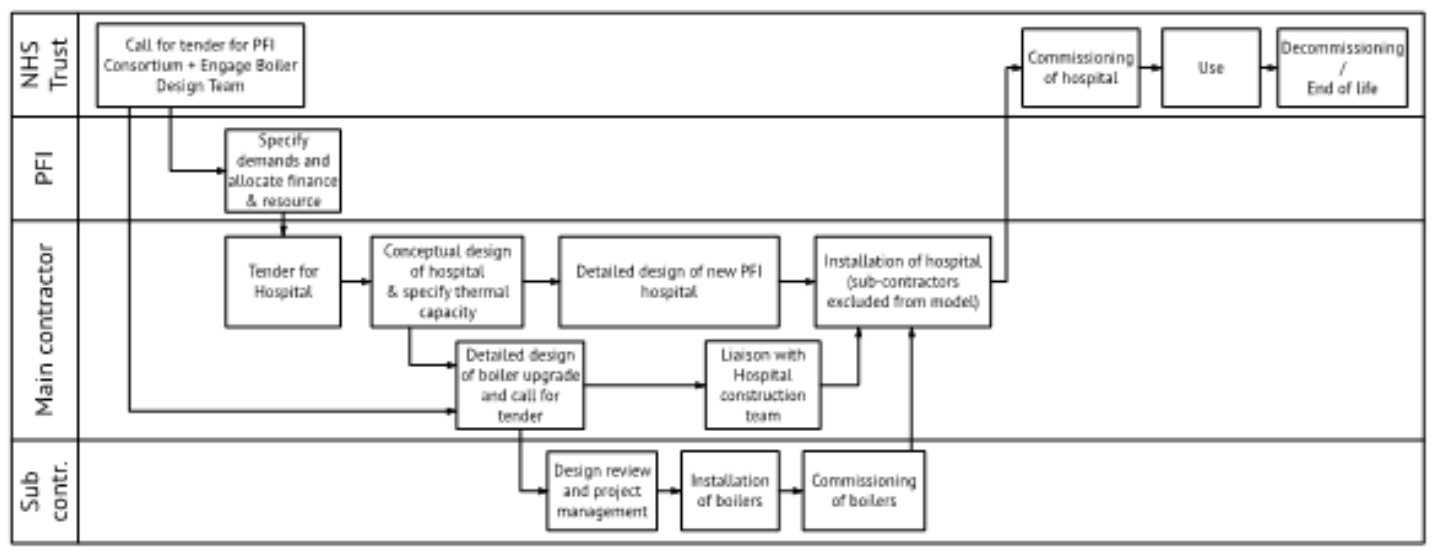

Figure 2. A process model of the boiler house project

\subsection{The cost of the margins}

The financial impact of excess margins that lead to oversizing of building services is apparent across the whole life-cycle of the installation. In the first instance, the capital cost of the boiler upgrade which includes the design, supply of equipment, the installation and commissioning increases in approximate proportion to the size of the installation, hence a system that is twice the size, is generally, twice the cost (Interview P11). Operating costs also increase when plant and equipment is oversized, this is due to a reduction in plant dynamic efficiency that results from the fact that oversized plant is permanently operating at lower load than its maximum duty point, hence leading to inefficiencies often associated with part-load operation. Hendrick states that "a $15 \%$ increase in energy consumption is possible if a conventional boiler plant is oversized by 150\%" (Hendrick et al., 1992); whilst boiler efficiencies have improved over time, the ratio of increased energy consumption versus oversizing remains proportional. Standing losses are radiated heat losses from a boiler when it is sitting idle on standby, and are typically quoted as being in the order of 3\% of the boiler installed capacity (Kenna and Bannister, 2009); the inefficiency of the installation is therefore relative to the size of the plant. Based on the case study boiler arrangement, whereby two and three boilers where in operation during the summer and winter respectively, standing losses can be calculated:

$$
\begin{aligned}
& 8.2 \mathrm{MW} \times 2 \text { boilers (summer six-month period) }=16.4 \mathrm{MW}(16,400 \mathrm{~kW}) \times 3 \%=492 \mathrm{~kW} \\
& 8.2 \mathrm{MW} \times 3 \text { boilers (winter six-month period) }=24.6 \mathrm{MW}(24,600 \mathrm{~kW}) \times 3 \%=738 \mathrm{~kW}
\end{aligned}
$$

Losses over a $12-$ month period $=[492 \mathrm{~kW} \mathrm{x} 4380 \mathrm{Hrs}]+[738 \mathrm{Kw}$ x $4380 \mathrm{Hrs}]=5,387,400 \mathrm{kWh}$.

Based on actual gas unit costs from invoices between April 2014 - March 2015; total standing boiler losses are anticipated to cost in the region of $2.9 \mathrm{p} / \mathrm{kWh} \times 5,387,400=£ 156,235$ p.a.

Based on the figures above, over the twenty-year life span of the boilers, standing losses will account for approximately $£ 3 \mathrm{M}$ worth of expenditure and CO2e emissions of 992 tonnes (DEFRA, 2017). Optimising the size of the boilers would have therefore significantly reduced the level of environmental pollution and expenditure associated with the oversizing of this plant. Oversizing can also lead to reduced plant life resulting in accelerated 'wear and tear' from on/off operation, rather than a continuous steady load. This can result in the premature replacement of plant and hence further cost implications. Boiler maintenance costs are also naturally affected by oversizing, as the larger the boiler components, valves, gaskets, feed-water pumps, pipework etc. the higher the cost to service or replace.

\section{Lack of process co-ordination as a possible reason for margins}

Figure 3 illustrates the design and installation sequence of a boiler upgrade project. The figure is in the form of a fishbone diagram, starting from client need on the left and moving through a central axis, over time, to 'operation and use' on the far right. Eight branches that signify main design stages extend from the central axis; each main branch then has a number of sub-branches that represent related design considerations. The figure illustrates that project development from left to right, over time, falls into 
distinct work stages. While the design process stages follow a sequence, it is not guaranteed that all information are shared with everyone in downstream phases, nor that if shared such assumptions are challenged (upstream communication). For example, a design engineer responsible for calculating the building heating load requirement, may not be explicit about assumptions made to those responsible for selecting the boiler profile and capacity; similarly, assumptions made when specifying the boiler capacity may then not be passed onto the boiler installers. Hence, choices made during one stage is not necessarily questioned or challenged when passed to the next stage; stakeholders accept decisions that have been made before them, and move on. In practice, some of the design tasks illustrated may be carried out simultaneously. It is important to note that despite the figure being a significant simplification of what is a very complex and fragmented design process, it does nonetheless provide an overview of the various boiler design stages, as well as highlight the fact that margins are applied throughout the design process. This figure includes a single feedback loop that informs future projects, however in practice, feedback loops between all tasks would be relevant and will inform a multitude of design considerations and choices, providing important structured learning outcomes to design and installation stakeholders.

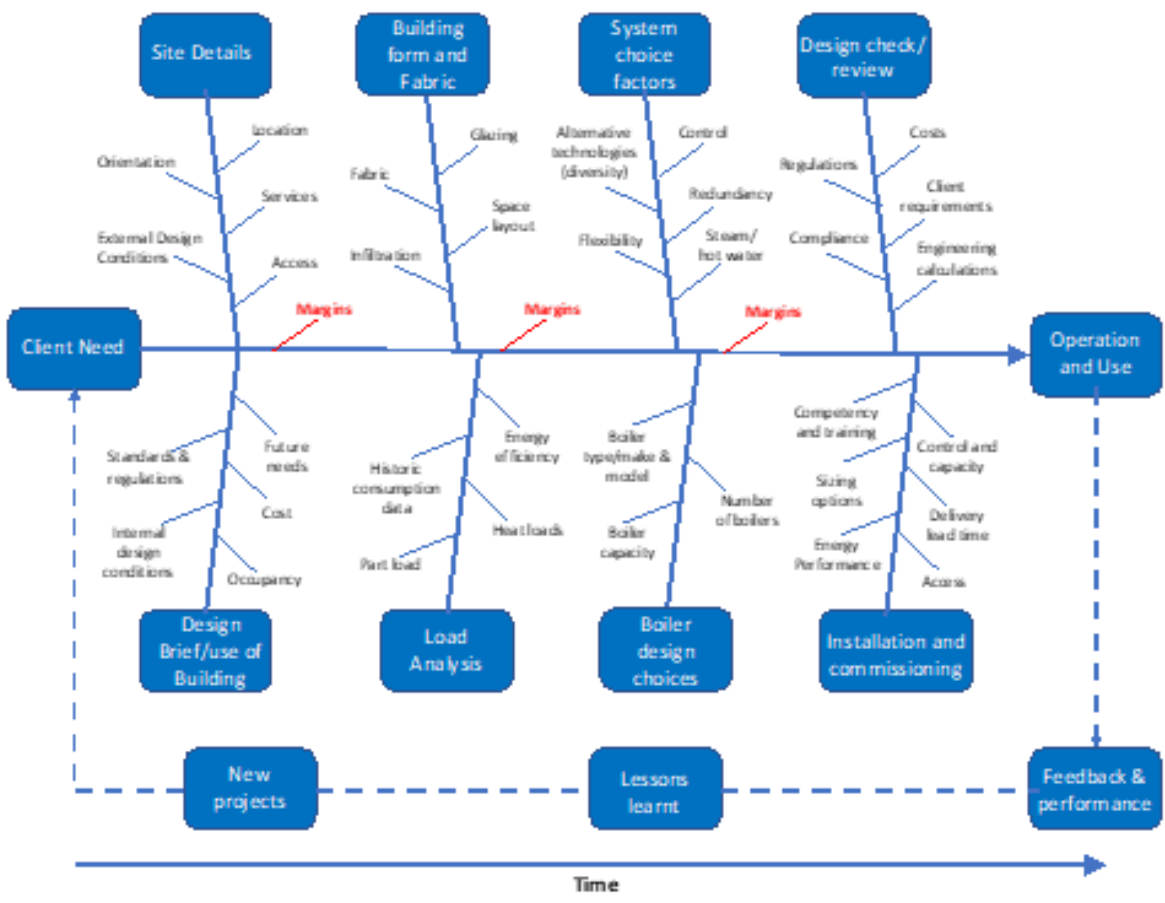

Figure 3. Sequence of design stages of a boiler upgrade process

To summarise, Figure 3 illustrates that there are a number of design groups that are each making decisions relative to their function and requirements, however it should be noted that no stakeholder group has visibility over the design process as a whole. In addition, due to the relative flow of work between the design, installation and commissioning groups, there is no ability to challenge the scope of margins applied, once these have been introduced by each group, and the design/installation has moved to the next stage. In essence, each group works to meet its own requirements without any thought as to what has been applied previously, thus providing another possible reason for the case study overdesign.

\subsection{Selection and oversizing of boilers - custom and practice}

To better understand the practical challenges associated with boiler selection, this section looks at various design considerations and decision points from a professional practise perspective (Interview P11). The type, use and size of a building affects the sizing of the boilers. Boilers can be sized for a "one hour heat up period" and will be larger than boilers, sized for a "two-hour heat up period". This is very seldom specified by the Client and is normally left to the Design Engineer to choose. The length of time 
for design programmes has reduced steadily over the last 30 years, hence is often insufficient time to revisit the calculations at the end of the design process, and therefore the preliminary design information is often used. The last few weeks of the design process is usually very intense due to a variety of reasons, which might include the arrival of late information or drawings. The design fees have also reduced over the last 30 years, this has reduced the amount of man hours available to revisit designs. If the Design Engineer is confident that the systems will work correctly, then the tendency is not to go back and reduce sizes of equipment, but to conform to the proposed design specification, despite this not being the optimum size. Once a specific capacity of boiler has been chosen there is then the issue of choosing a specific product from a specific manufacturer. For example, if the choice is $3 \times 1.2 \mathrm{MW}$ boilers, it may be that a specific manufacturer only makes a boiler of $1 \mathrm{MW}$ and the next size up is $1.5 \mathrm{MW}$, hence there is a tendency to select the larger boilers, as this provides the necessary assurance that a buildings heating requirement is met. When the design requirement is being calculated, a worst case is considered; the heat loss from building fabric and air infiltration losses, give this worst case. There are however, heat gains from humans (approximately $100 \mathrm{~W}$ per person) which when considered in the context of a large hospital that may occupy over 4,000 people, can account for gains of $400 \mathrm{~kW}(0.4 \mathrm{MW})$. In addition, there are many other types of equipment that give out heat within buildings such as fridges, IT equipment etc. In hospitals, medical equipment such as MRI scanners give off so much heat that they need to be permanently cooled. None of the people or equipment gains (generally referred to as internal heat gains) are taken into account when the heat loss calculations are undertaken. Consequently, the peak load that is delivered to the building is often much less than the design-heating load. One other major item that affects design outcomes is that wrong information is provided by third parties, to include for future buildings. There have been a number of recorded incidents of projected loads being significantly more than loads that have been realised in practice; leading to significantly oversized plant.

\section{Discussion}

The analysis reveals three potential reasons for the case study overdesign. One possible reason is due to the large range of margins, and margin values that are quoted within building services guidance documents that lead to confusion and ambiguity. This is exasperated by the fact that there is little published guidance on the best use of these margins, hence design engineers are left to decide where to add these, and to what extent, based on prior experience 'custom and practice' and the use of 'rules of thumb'; hence there is a general lack of understanding as to what extent the current design guides are adding to the over sizing issue. A second probable reason for the overdesign is due to overstated requirements and customary redundancy. It is apparent from the research findings and subsequent modelling that a principal contributor to the oversized boiler capacity was the over specification of thermal capacity by the PFI hospital, engineering design team. Adding to this already overstated specification is the anticipated application of a precautionary redundancy factor, by the Trust side boiler design team. Thirdly as discussed in Section 5, the overdesign may have been due to a lack of process co-ordination, poor communications and ineffective management between project design, installation and commissioning stakeholders. Whilst all the above scenarios are all very plausible reasons for the over design, the reality is that the overdesign is likely to be the result of a combination of the three. In order to estimate the thermal requirement of the new hospital; which we understand from our analysis was undertaken during the conceptual design stage, the PFI design team would have had to make assumptions relating to; the building construction materials, occupancy numbers, building use, internal heat gains, weather effect and building orientation. Building design guides are likely to have been used to support any assumptions made, or at the very least 'building benchmarks' such as those published in CIBSE Guide F - 'Energy Efficiency in Buildings', used to estimate the hospital thermal (heating and hot water) requirement, based on the known footprint of the site and the building type (CIBSE, 2004).

It is therefore not surprising that the likely use of such vague and imprecise methods to estimate the required thermal capacity, coupled by the fact that the PFI design would have almost certainly been cautious (to safeguard against any financial or operational penalties) that the requirement of $12 \mathrm{MW}$ had been over stated. Another important finding of the research was that the rationale behind the specification requested by the PFI team did not appear to be shared with the Trust design team. This led an assumption being made by the Trust design team that no redundancy factor had be incorporated into the $12 \mathrm{MW}$ 
specification, and therefore this was subsequently applied. The effects of all 'causes' of the over design could be mitigated by a 'systems architect' overseeing and coordinating the fragmented process and having the required holistic understanding of the system (building), all stakeholders, and the process.

Despite a thorough review of the project documentation and detailed conversations with relevant project stakeholders, the research did not allow the authors to specifically determine the different margins, and where these were applied during the specification, design and installation processes. Subsequent modelling of the process did, however, reveal some clear gaps in understanding relating to stakeholder arrangements and decision points; these gaps in knowledge were subsequently closed by conducting further verification interviews. Experience of the first author, which is supported by similar literature examples of system oversizing suggests that whilst the case study example is extreme, it is not untypical and despite a general awareness and acceptance of the issue of overdesign in building services, this remains an ongoing industry problem; from the perspective of NHS Trusts that have an ever-growing need to operate their buildings efficiently in order to meet binding energy efficiency targets, oversized infrastructure is a significant barrier. Looking at this from a construction or building services industry perspective (designers, suppliers and installers), it could be argued that oversizing is an advantage as this lessens the risk of not meeting client requirements, but also provides greater fee earning opportunities, relative to the size and cost of equipment. This might to some extent explain why this issue is not being tackled. It is not entirely clear from this research, where, or by whom margins have been added or indeed why the boiler upgrade is so grossly oversized. What the research does reveal however, is that there is a general lack of systemic thinking within the design process across multiple project stakeholders and a lack of traceability and accountability associated with the capture and recording of requirements and decision choices; it is important to stress, however, that this issue is not specific to building design but specific to any complex (and fragmented) design activity. The recording of margins throughout the design process is likely to reduce the accumulation of hidden margins; the development of a margin register that captures all margins and assumptions, may therefore be of benefit. A practical check of requirements that compares the intended design specification with post commissioning feedback, may also prove useful.

\section{Conclusions}

Design margins arise from a lack of systemic thinking during the predevelopment, design and installation phases. Whilst the case study overdesign is striking, margins were rarely discussed in the documentation and the rationale for the margins are lost; the importance of traceability can therefore not be over emphasised. The process analysis revealed a highly complex process, where capacity values and design decisions are passed on as requirements in tender documents for which no rationale or flexibility is provided. As discussed in the literature, the issue of over sizing is not unique to the NHS, but is an industry wide issue that affects the majority of commercial buildings. While being an extreme case, the same can certainly be observed as a 'natural' consequence of the conservative engineering mindset that leads to the addition of margins to mitigate lacking information (necessary to design safe systems) in any system that is being created without proper mechanisms such as specific roles like systems architects, harmonised processes across multiple teams, or software support (e.g. PDM systems). Adopting a systemic thinking approach to design practise will therefore support and encourage improved communications between project stakeholders and provide better traceability and accountability of design choices, such as the application of margins; this will inevitably lead to improved efficiency benefits within the building services industry, as well as the wider design community.

\section{References}

Almefelt, L. (2005), "Balancing Properties While Synthesising a Product Concept-A Method Highlighting Synergies", Proceedings ICED'05 / the 15th International Conferenceon Engineering Design, Melbourne, Australia, August 15-18, 2005.

Bacon, M. (2014), "Occupancy Analytics: A New Basis for Low-Energy-low-Carbon Hospital Design and Operation in the UK", Architectural Engineering and Design Management, Vol. 10 No. 1-2, pp. 146-163. https://doi.org/10.1080/17452007.2013.837254 
Banerjee, P. and de Weck, O. (2004), "Flexibility Strategy - Valuing Flexible Product Options", Proceedings of INCOSE/ICSE conference on synergy between systems engineering and project management, Las Vegas, Nevada.

Boardman, J. and Sauser, B. (2006), "System of Systems-the Meaning of Of”, Proceedings of the 2006 IEEE/SMC International Conference on System of Systems Engineering, Los Angeles, CA, USA, July 24 - 26, 2006, IEEE, pp. 118-123. https://doi.org/10.1109/SYSOSE.2006.1652284

Bownass, D. (2001), Building services Design Methodology, A Practical Guide, SPON Press, London. https://doi.org/10.4324/9780203478707

BSRIA (2007), A Guide to HVAC Building Services Calculations, 2nd ed., BSRIA, Berkshire.

Chartered Institute of Building Service Engineers (1986), Volume B - Installation and Equipment Data, CIBSE, London.

Chartered Institute of Building Service Engineers (1998), Engineering design calculations and the use of margins, CIBSE, London.

Chartered Institute of Building Service Engineers (2004), Guide F - 'Energy Efficiency in Buildings', CIBSE, London.

Chen, C. and Crilly, N. (2014), "Modularity, Redundancy and Degeneracy: Cross-Domain Perspectives on Key Design Principles", 8th Annual IEEE Systems Conference (SysCon), Ottawa, Canada, IEEE, pp. 546-553. https://doi.org/10.1109/SysCon.2014.6819309

Crozier, B. (2000), Enhancing the Performance of Oversized Plant (AG 1/2000), BSRIA, Berkshire.

de Neufville, R., de Weck, O., Frey, D., Hastings, D., Larson, R. et al. (2004), "Uncertainty Management for Engineering Systems Planning and Design", Engineering Systems Symposium, March 29-31, 2004, MIT esd.

de Neufville, R., Scholtes, S. and Wang, T. (2006), "Real options by spreadsheet: parking garage case example", Journal of infrastructure systems, Vol. 12 No. 2, pp. 107-111. https://doi.org/10.1061/(ASCE)10760342(2006)12:2(107)

DEFRA (2017), Conversion factors - Condensed set for most users v02-00. [online] DEFRA. Available at: https://www.gov.uk/government/publications/greenhouse-gas-reporting-conversion-factors-2017

Djunaedy, E., van den Wymelenberg, K., Acker, B. and Thimmana, H. (2011), "Oversizing of HVAC System: Signatures and Penalties", Energy and Buildings, Vol. 43 No. 2-3, pp. 468-475. https://doi.org/10.1016/j.enbuild.2010.10.011

Eckert, C., Earl, C., Lebjioui, S. and Isaksson, O. (2013), "Components Margins through the Product Lifecycle", Proceedings of PLM 2013 / the 10 $0^{\text {th }}$ IFIP International Conference on Product Lifecycle Management, Nantes, France, July 6-10, 2013, Springer, Berlin, Heidelberg, pp. 39-47. https://doi.org/10.1007/978-3-642-4150125

Hendrick, R.L., Witte, M.J., Leslie, N.P. and Bassett, W.W. (1992), "Furnace sizing criteria for energy-efficient setback strategies", ASHRAE Transactions, Vol. 98, pp. 1239-1246.

Jones, D.A. and Eckert, C.M. (2016), "Design Margins: Impact on Building Energy Performance", Proceedings of the DESIGN 2016 / 14th International Design Conference, The Design Society, Glasgow, pp. 1295-1304.

Kenna, E. and Bannister, P. (2009), "Simple, fully featured boiler loop modelling", 11th International IBPSA Conference, Glasgow, Scotland, July 27 - 30, 2009, pp. 428-433.

Möller, N. and Hansson S.O. (2008), "Principles of engineering safety: Risk and uncertainty reduction", Reliability Engineering and System Safety, Vol. 93 No. 6, pp. 776-783.https://doi.org/10.1016/j.ress.2007.03.031

NHS (2017), The NHS in England. [online] National Health Service. Available at: https://www.nhs.uk/NHSEngland/thenhs/about/Pages/overview.aspx (accessed: 06.11.2017)

Race G.L. (2007), Design Checks for HVAC - A Quality Control Framework, 2nd ed., BSRIA, Berkshire.

Ross, A.M. and Hastings, D.E. (2005), "The tradespace exploration paradigm", INCOSE International Symposium, Vol. 15 No. 1, pp. 1706-1718. https://doi.org/10.1002/j.2334-5837.2005.tb00783.x

Stratmann, J. (2006), Engineering Management of Early Stage Warship Design, PhD thesis, University of Southampton.

Tackett, M.W., Mattson, C.A. and Ferguson, S.M. (2014), “A Model for Quantifying System Evolvability Based on Excess and Capacity", Journal of Mechanical Design, Vol. 136 No. 5, pp. 051002. https://doi.org/10.1115/1.4026648

The Telegraph (2017), The PFI hospitals costing NHS £2bn every year. [online] The Telegraph. Available at: http://www.telegraph.co.uk/news/nhs/11748960/The-PFI-hospitals-costing-NHS-2bn-every-year.html (accessed 06.11.2017)

Darren Anthony Jones, PhD Student

The Open University, STEM-EI

MK7 6AA Milton Keynes, United Kingdom

Email: daj87@my.open.ac.uk 